\title{
INFLUENCE OF PREANNEALING ON PERFECTION OF CZOCHRALSKI GROWN SILICON CRYSTALS SUBJECTED TO HIGH PRESSURE TREATMENT
}

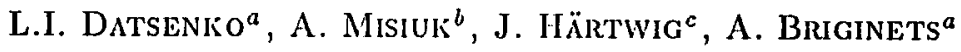 \\ AND V.I. KHRUPA ${ }^{a}$ \\ a Institute of Semiconductor Plysics, National Academy of Sciences \\ Prosp. Nauki 45, 252028 Kíev-28, Ukraine \\ ${ }^{b}$ Institute of Electron Technology, Al. Lotuików 32/46, 02-668 Warszawa, Poland \\ ${ }^{c}$ Experiments Division of ESRF, BP 220, 38043 Grenoble Cedex, France
}

The effect of high temperature (up to $1120^{\circ} \mathrm{C}$ )-ligh pressure (up to $1.1 \mathrm{GPa}$ ) treatment on the resulting defect structure of preannealed (450-725 $\mathrm{C}$, up to 96 hours) Czochralski grown Si crystals was studied by $\mathrm{X}$-ray diffraction. The values of the Debye-Waller static factor and of the root-mean-square atomic displacement due to defects were determined for various Laue reflections. Well-defined development of the cluster like defect structure after ligh temperature pressurization depending to a substantial extent on the preannealing conditions was observed.

PACS numbers: $61.70 .-r, 81.40 .-z$

\section{Introduction}

Formation of the bulk gettering centres for decontamination of Czochralski grown silicon crystals, $\mathrm{Cz}-\mathrm{Si}$, from undesirable impurities is one of the important technological operations during production of solid state devices. Such centres are known to be composed mainly of $\mathrm{SiO}_{x}$ precipitates. These defects are formed in particular during annealing of a crystal at the expense of the oxygen solid solution decay. Such a decay starts from the appearance of rather small structure imperfections (nucleation centres) during low temperature (at $450-725^{\circ} \mathrm{C}$ ) preannealing. Nucleation centres grow further with increasing temperature to form comparatively large $\mathrm{SiO}_{x}$ precipitates.

It is known that the high tempcrature pressurization can modify the process of defect structure formation in $\mathrm{Cz}-\mathrm{Si}$ crystals $[1,2]$. An external stress introduced for instance by subjecting the samples to hydrostatic pressure can affect the strain 
at the matrix-oxygen precipitate boundary and, as a result of it, can essentially change also the oxygen precipitation process. Therefore it is of interest to study the effect of high temperature-high pressure treatment on the resulting defect structure of preannealed $\mathrm{Cz}-\mathrm{Si}$.

Formation of any defect structure in periodic media results in changing the integral perfection characteristics which can be determined by investigation of various phenomena related to $X$-ray dynamical scattering $[3,4]$. The aim of this paper was X-ray diffraction examinalion of resulting structure perfection of $\mathrm{Cz}-\mathrm{Si}$ crystals subjected to preannealing at different temperatures and then to the high temperature-high pressure treatment.

\section{Experimental}

$\mathrm{Cz}-\mathrm{Si}$ samples with the initial oxygen concentration, $C_{0}$, up to $1 \times 10^{18} \mathrm{~cm}^{-3}$ were preannealed under pressure of $10^{5} \mathrm{~Pa}$ (Table I). The samples were then subjected to the high temperature--ligh hydrostatic pressure treatment (hydrostatic pressure up to $1.1 \mathrm{GPa}$, temperature up to $1120^{\circ} \mathrm{C}$ ) for up to 5 hours. The sample defect structure was investigated by means of white beam topography, selective chemical etching and other methods.

The different Laue-diffraction orders $(220,440,660$ and 880$)$ were used for registration of the integral reflectivities, $R_{\mathrm{i}}$, of samples. Such an approach is sensitive to presence of the structure defects and permits to measure the integral characteristics of crystal perfection. It is possible to estimate, i.e., the values of the static Debye-Waller factor, $L$, and of the root-mean-square atomic displacement, $U$, from the position of equilibrium due to defects [4] as well as to identify the predominant type of imperfections [5].

The use of the Mo $K_{\alpha}$-radiation provided fulfillment of a thin crystal approximation $(\mu t \approx 0.5$, where $\mu$ and $t$ stand for the absorption coefficient and thickness, respectively) for all of the samples. Under such conditions the $R_{\mathrm{i}}$ increments in crystals with structure distortions should be observed at the expense of diffuse scattering as compared with the $R_{\mathrm{i}}$ value for a perfect sample. This increment of reflectivity rises with the structure distortion level.

White beam topographs were obtained at LURE, the synchrotron radiation source in Orsay, France, in the regime of extinction contrast (331 Laue-reflections, $\lambda \approx 0.5 \AA$ ).

\section{Results and discussion}

The integral reflectivity logaritlum versus the order $N=\sqrt{h^{2}+k^{2}+l^{2}}$ of Laue-diffraction, where $h, k, l$ are Miller's indices for the sample numbers $1,2,3$ and 4, is shown in Fig. 1. The solid line was obtained by calculation of $R_{\mathrm{i}}$ for a perfect $\mathrm{Si}$ crystal. The experimental data are given by points for all the samples. One can see that the positions of these points for all reflections are noticeably shifted along the ordinate axis due to enliancement of structure imperfection with higher preannealing temperature. The maximum increments of the integral reflectivity for all samples are observed for the 880 reflection. The values of Debye-Waller factor $L$ as well as the root-mean-square displacements, $U$, of atoms from "average" 
TABLE I

Structure perfection of $\mathrm{Cz}-\mathrm{Si}$ samples with initial $C_{0}=6.5 \times 10^{17} \mathrm{~cm}^{-3}$ preannealed at different conditions and subjected to high temperature-high pressure treatment $\left(T=1120^{\circ} \mathrm{C}, P=1.1 \mathrm{GPa}\right)$.

\begin{tabular}{c|c|c|c|c|c}
\hline \hline $\begin{array}{c}\text { Sample } \\
\text { number }\end{array}$ & $\begin{array}{c}\text { Parameters } \\
\text { of preannealing } \\
\text { (time, temperature) }\end{array}$ & $\begin{array}{c}\text { Reflection } \\
h k l\end{array}$ & $L \times 10^{2}$ & $U \times 10^{2}[\AA]$ & $\begin{array}{c}C_{0} \times 10^{-17} \\
{\left[\mathrm{at.}^{-3}\right]}\end{array}$ \\
\hline 1 & $96 \mathrm{~h}, 450^{\circ} \mathrm{C}$ & 220 & 0.3 & 2.4 & 6.42 \\
& & 440 & 1.0 & 2.1 & \\
& & 660 & 3.4 & 2.6 & \\
\hline 2 & $96 \mathrm{~h}, 650^{\circ} \mathrm{C}$ & 220 & 1.4 & 5.1 & 4.26 \\
& & 440 & 3.7 & 4.2 & \\
& & 660 & 8.4 & 4.2 & \\
& & 880 & 15.1 & 4.2 & \\
\hline 3 & $96 \mathrm{~h}, 450^{\circ} \mathrm{C}$ & 220 & 2.2 & 6.0 & 2.73 \\
& $+96 \mathrm{~h}, 650^{\circ} \mathrm{C}$ & 440 & 6.0 & 5.3 & \\
& & 660 & 12.1 & 5.0 & \\
& & 880 & 22.2 & 5.1 & \\
\hline 4 & $96 \mathrm{~h}, 725^{\circ} \mathrm{C}$ & 220 & 2.7 & 7.1 & 3.21 \\
& & 440 & 8.0 & 6.1 & \\
& & 660 & 20.3 & 6.4 & \\
& & 880 & 37.2 & 6.5 & \\
\hline
\end{tabular}

$L$ and $U$ stand for the static Debye-Waller factor and the value of root-mean-square atomic displacements, respectively. Oxygen interstitials concentration $C_{0}$ was determined by infrared spectroscopy.

lattice due to created defects were calculated from the $R_{\mathrm{i}}$ data according to the described procedure [4] (Table I). Both these parameters rise with increasing of a sample number, i.e. with higher preannealing temperature.

The final effect of high temperature-high pressure treatment is dependent also on the initial oxygen concentration, $C_{0}$, and on the hydrostatic pressure, $P$, value, in addition to the preliminary annealing conditions. An influence of the above indicated parameters for the case of a sample preannealed at $725^{\circ} \mathrm{C}$ for 20 hours is presented in Table II. From comparison of the integral parameters of structure perfection for the samples No. 5 and 6 as well as No. 7 and 8 it follows that the final structure perfection is worse in the case of $\mathrm{Cz}-\mathrm{Si}$ samples with the higher initial $C_{0}$ value. On the other hand, the structure perfection is better, in the case of $C_{0}=$ const, for the lower value of pressure applied during the 
TABLE II

Integral parameters of structure perfection, $L$ and $U$, of $\mathrm{Cz}-\mathrm{Si}$ samples with different initial oxygen concentrations, $C_{0}$, subjected to preannealing at $725^{\circ} \mathrm{C}$ for 20 hours and then to high temperature-high pressure treatment under different hydrostatic pressures.

\begin{tabular}{|c|c|c|c|c|}
\hline Sample number & $\begin{array}{l}C_{0} \times 10^{-17} \\
{\left[\text { at. } \mathrm{cm}^{-3}\right]}\end{array}$ & $\begin{array}{l}\text { Treatment conditions } \\
T\left[{ }^{\circ} \mathrm{C}\right] ; P[\mathrm{~Pa}] ; \text { hour }\end{array}$ & $L_{660} \times 10^{2}$ & $U \times 10^{2}[\AA]$ \\
\hline 5 & 6.5 & $1120 ; \quad 10^{7} ; \quad 5$ & 3.93 & 2.8 \\
\hline 6 & 10 & $1120 ; \quad 10^{7} ;$ & 8.78 & 6.1 \\
\hline 7 & 6.5 & $1120 ; \quad 10^{9} ;$ & 6.01 & 3.6 \\
\hline 8 & 10 & $1120 ; \quad 10^{9}$ & 20.5 & 6.7 \\
\hline
\end{tabular}

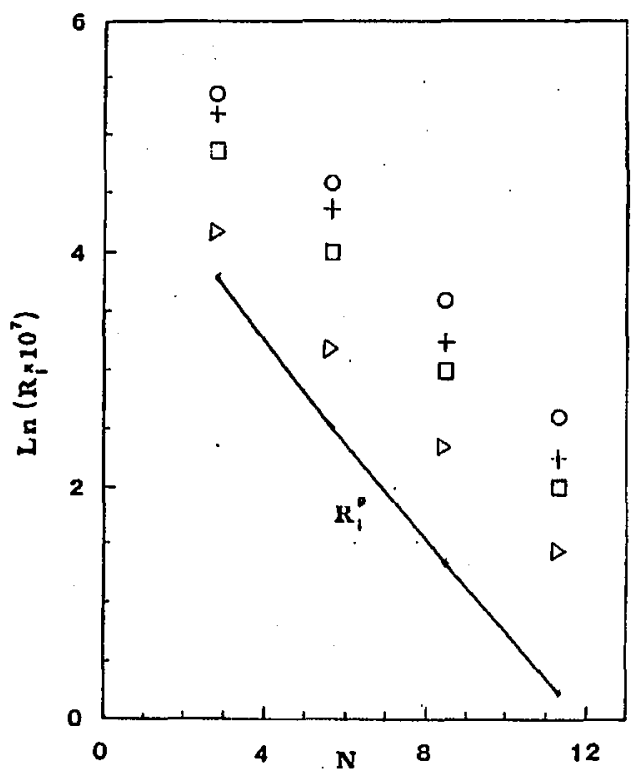

Fig. 1. Integral reflectivity $R_{\mathrm{i}}$ as a function of the Laue diffraction order, $N$, for the samples No.1 $\div 4$ subjected to various conditions of preannealing (see Table I). $\Delta-$ No. 1, $\square-$ No. $2,+-$ No. 3 , o- No. 4 .

pressure-temperature treatment (compare the samples No. 5 and 7 as well as No. 6 and 8). The last observation means that a sulliciently ligh hydrostatic pressure can change the level of structure distortion at the matrix/ $\mathrm{SiO}_{x}$ phase boundary and thus makes it possible to create the additional defects at this boundary $[1,2]$. 


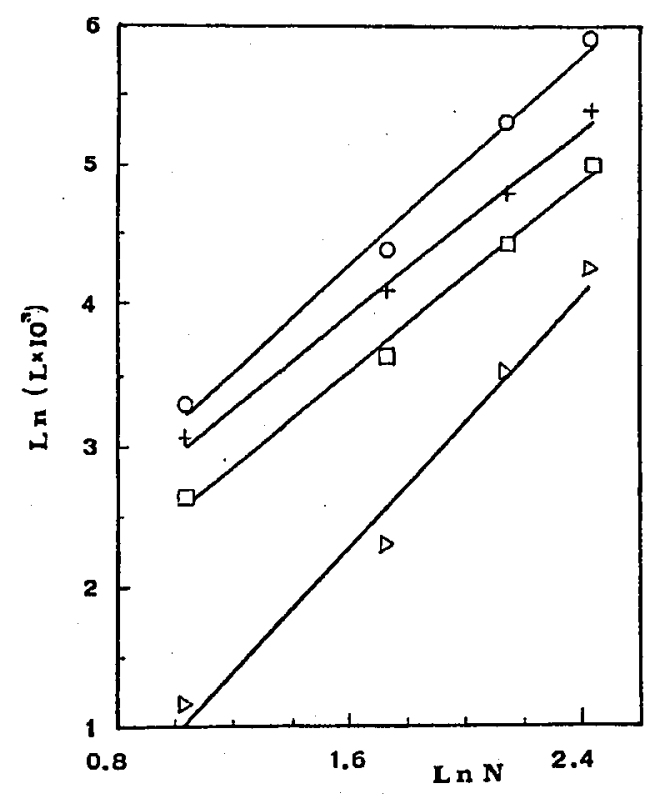

Fig. 2. Logarithm of the Debye-Waller static factor as a function of logarithm of the diffraction order for the samples No. $1 \div 4$. The samples are marked as in Fig. 1 .
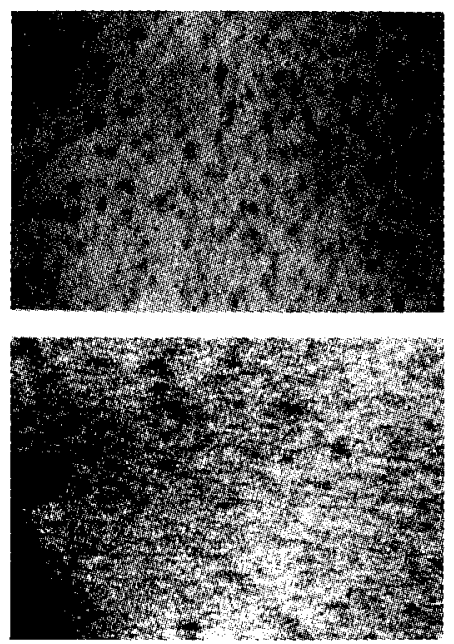

a

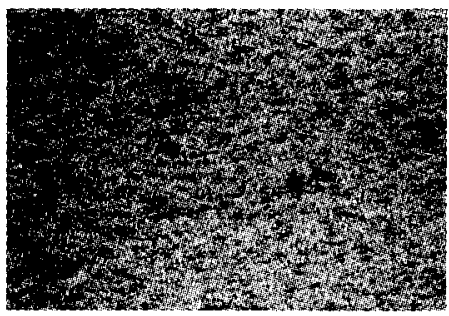

C

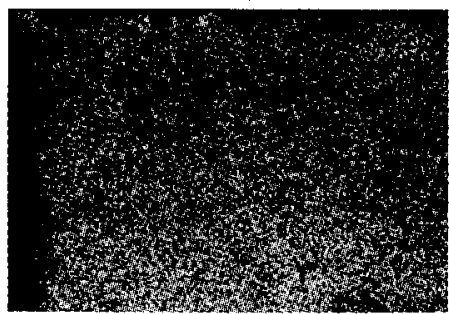

d

Fig. 3. White beam topographs obtained by means of the $\mathrm{X}$-ray continuous spectrum: (a) the sample No. 1; (b) No. 2; (c) No. 3; (d) No. 4; magnification $\times 50$; 331-reflection, radiation wavelength near $0.5 \AA$. 
The corresponding graphs of the $\ln L=f(\ln N)$ dependence are shown in Fig. 2. These graphs are shifted monotonically along the $Y$-axis as the preannealing temperature rises. But the values of the slopes of all graphs are close to 2 which confirms the presence of cluster like defects in samples according to the known theory [5].

All obtained parameters which characterize the crystal structure perfection quantitatively demonstrate the well-defined development of the defect structure during high temperature pressurization depending to a great extent on the preannealing conditions. The white beam topographs (Fig. 3) also confirm the formation of the cluster-like defects, the density of which rises as the above-mentioned preannealing temperature increases. So the topographic results confirm the conclusions obtained from the $\mathrm{X}$-ray analysis of integral reflectivity behaviour.

\section{Conclusions}

The structure perfection degree of $\mathrm{Cz}-\mathrm{Si}$ subjected to the high temperaturehigh pressure treatment depends essentially on the preannealing conditions, the oxygen concentration, $C_{0}$, in $\mathrm{Cz}-\mathrm{Si}$ and on the treatment parameters.

After the high temperature -high pressure treatment at $1120^{\circ} \mathrm{C}-1.1(1.0) \mathrm{GPa}$ - 4 hours the structure perfection of $\mathrm{Cz}-\mathrm{Si}$ samples was much worse in the case of higher preannealing temperature. For example, the $U$ value was about 3 times higher for the samples with initial $C_{0}=6.5 \times 10^{17} \mathrm{~cm}^{-3}$ preannealed at $725^{\circ} \mathrm{C}$ for 96 hours as compared to that preannealed at $450^{\circ} \mathrm{C}$. The structure perfection is dependent also on the $C_{0}$ value (worsening with a rise of the oxygen concentration) and on the $P$ value (also worsening with a rise of the hydrostatic pressure).

\section{Acknowledgments}

This work has been supported in 1992-94 by the grant of the State Committee for Scientific Research (Republic of Poland) (project No. 88027 92 03) and by Ukrainian Committee for Scientific Research and Technology.

\section{References}

[1] A. Misiuk, Solid State Plkenomena 19-20, 387 (1991).

[2] A. Misiuk, J. Adamczewska, J. Bąk-Misiuk, J. Wolf, ibid. 32-33, 167 (1993).

[3] L.I. Datsenko, V.B. Molodkin, M.E. Osinovskii, Dynamicheshoe rasseyanie rentgenouskikh lutchey realnymi kristallami, Naukova Dumka, Kiev 1988, p. 198 (in Russian).

[4] V.I. Khrupa, Metallofizika 13, 49 (1991).

[5] P.H. Dederichs, Phys. Rev. B 1, 1306 (1970). 